\title{
Geophysics Investigation and Monitoring Applied to Tailings Dam
}

Roberto Albuquerque ${ }^{1}$, Marco Antônio Braga ${ }^{1}$, Lorena Andrade Oliveira' ${ }^{1}$, Leonardo Santana de Oliveira Dias ${ }^{1}$, Luis Antônio Pinto Almeida ${ }^{2}$, Arildo Henrique de Oliveira ${ }^{2}$ and Silvana Brandão Cembranelli2 ${ }^{2}{ }^{1}$ UFRJ and ${ }^{2}$ Mosaic Fertilizantes

Copyright 2019, SBGf - Sociedade Brasileira de Geofísica

This paper was prepared for presentation during the $16^{\text {th }}$ International Congress of the Brazilian Geophysical Society held in Rio de Janeiro, Brazil, 19-22 August 2019.

Contents of this paper were reviewed by the Technical Committee of the $16^{\text {th }}$ International Congress of the Brazilian Geophysical Society and do not necessarily represent any position of the SBGf, its officers or members. Electronic reproduction or storage of any part of this paper for commercial purposes without the written consent of the Brazilian Geophysical Society is prohibited.

\section{Abstract}

Tailing dams are structures widely used in the mining industry. These structures are monitored by instruments such as piezometers, topographic benchmarks and borehole standpipes on a daily basis. Some geophysical methods have been developed in addition to this monitoring. Despite this, in Brazil, the use of geophysics for evaluation and monitoring of mining dams is not a common practice. The B1 dam, which is part of the Cajati Mining Site (Mosaic Fertilizantes), in São Paulo state, was chosen to be evaluated on the use of electric resistivity. The present work aims to discuss the geophysical results from this dam, as well as to analyze the applicability of the geophysical method as a way of evaluate the internal conditions of the structure's embankment. Initially, eight electrical 2D profiles were acquired. From the analysis of these profiles, a low resistivity zone - ZLR could be observed on the first two sections, corresponding to the localization of the clay core. The were consistent with the water level normally observed in the water level indicators located near the crest of the dam. ZLRs were observed both along the right abutment and next to the left abutment. In order to further investigate these ZLRs, a new electrical campaign was performed covering the left abutment with new geophysical sections. After a more thorough analysis of the engineering projects, the information emerged that there were discharge channels of old spillways filled by a blanket drain. The ZLRs observed in the new sections coincide with these structures, possibly conditioned by water percolation. The data obtained with the application of the Electric Resistivity method are coherent with the structure of the dam, being in harmony with the measurements of the instruments that monitor the dam. Geophysics, as demonstrated, complements the dam instrumentation, and gives a broader view of the distribution of moisture in the embankment, showing its behavior in stretches that are not covered by the usual instrumentation.

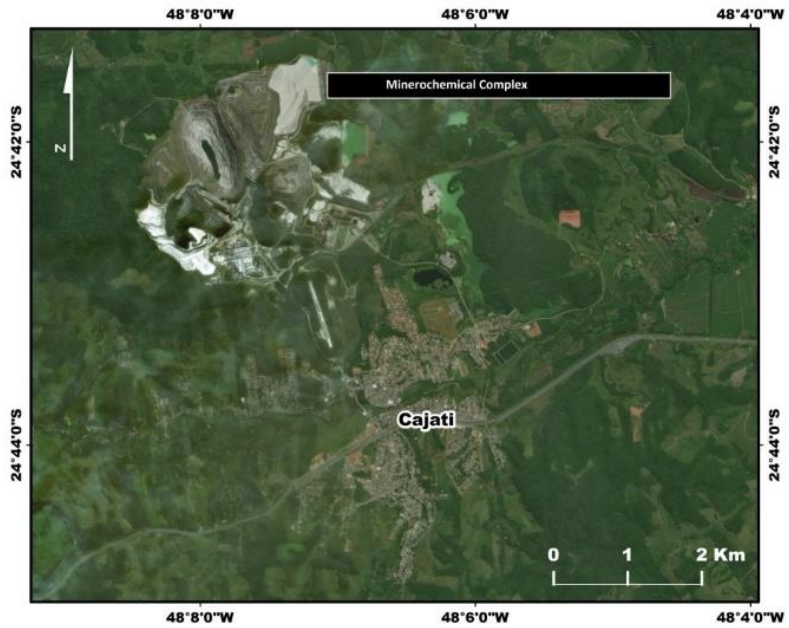

Figure 1 - Location of the Cajati Minerochemical Complex (modified from World Imagery Basemap - ArcGis ESRI, 2017).

\section{Introduction}

Tailing dams are structures that are widely used in mining, aiming for the final disposal of ore beneficiation residues. These structures deserve special attention from the design phase to the mine closure. They are monitored in day by day of operation with instruments such as: piezometers, topographic landmarks, water level meters, etc. These instruments provide direct information on the structure and on the behavior of water within the body of the dam. In addition to the use of instruments, routine visual inspections are made observing the presence of cracks, water surges, erosions, etc. The conservation status of gutters and spillways should also be checked. Some geophysical methods have been used as a complement to these inspections, either to observe the structure of the dam mass, as in SJÖDAHL et al. (2005), or to evaluate some identified emergence, such as SJÖDAHL et al. (2008); JOHANSSON, (1997) and PANTHULU et al., (2001). Electric Imaging, raising Spontaneous Potential (SP) and Resistivity were performed at Kiruna, Aitik and Kristineberg tailings dams in Sweden to observe groundwater level and identify areas of water saturation and anomalous upwelling (MAINALI, 2006).

In Brazil, the use of geophysics for evaluation and monitoring of mining structures is not a usual practice. The Center for Research in Applied Geophysics (CPGA) of the Department of Geology of UFRJ aims to develop the use of geophysical solutions of various problems of industry and people's daily lives, and therefore, began a project in order to study and diffuse the application of geophysics in tailing dams. One of the dams selected in this project is the B1 Dam of the Cajati Mineral-Chemical Complex, which will be described below. 
In this work the results of the application of Electric Resistivity in Cajati tailings dam will be discussed.

\section{Dam B1}

The B1 dam started with a dyke in 1973 with approximately $15.0 \mathrm{~m}$ of height, built with compacted clayey landfill, presenting a downstream footfall. For the construction of the starting dam, the 1 to $2 \mathrm{~m}$ thick layer of clayey soil with a soft consistency covering the region was not removed. Afterwards, it underwent successive small increases, resulting in a zoned massif with an upstream impervious zone (clayey septum), the upstream and downstream parts being made of permeable material consisting of limestone tailings. Downstream of the starting dike, we can see a vertical sand filter associated with a drainage mat formed by running gravel which is interconnected to the footing of the structure drain.

The instrumentation of the B1 dam consists of 1 Casagrande (PZ) piezometer, 6 electrical piezometers (PZE), 13 water level indicators (INA), 9 surface landmarks (MS), 1 graduated ruler in the reservoir and 1 rain gauge. The INAs are distributed in 5 profiles transversal to the axis of the dam. The reject consists of: calcite (65.6\%), dolomite $(23.9 \%)$, apatite $(7.2 \%)$ and mica $(1.2 \%)$.

\section{Method}

For the geophysical investigation, the chosen method was the electric resistivity, acquired through electrical profile. Initially, 8 profiles (L01-L08) were surveyed, with spacing between the lines from 10 to 15 meters, totalizing 2,215 meters of electrical data.

The profiles were acquired (L01 to L08) parallel to the axis of the dam. At the beginning of the surveying, tests were performed using different electrode arrays, in order to determine the best methodology for the acquisition. The tests were carried out along the L01 with the Dipole-Dipole and Gradient arrays. The array chosen for the electric surveying was the Dipole-Dipole, because it presented better signal-to-noise ratio and satisfactory relation depth of investigation versus lateral resolution. Due to the results obtained in lines L01 to L08, a new geophysical campaign was done to cover the left abutment of the dam. In the new acquisition, 6 electrical profiles (L09 to L14) were performed, with equal spacing of 3 meters between the electrodes. In this stage, there were 1,116 meters of data acquisition. After the survey, these were interpreted and integrated in order to understand the resistivity behavior of the dam mass. The interpretation occurred together with the engineering project of $\mathrm{B} 1$ in order to verify if the geophysical response of the mass was compatible with the material present in the location of the sections.

\section{Results}

The surveyed profiles, L01 to L14, reached depths of 30 to 40 meters, and were efficient in the detection of low and high resistivity anomalies.

In sections L01 and L02, a zone of low resistivity (ZBR), with values below $84 \mathrm{ohm} . \mathrm{m}$, is observed from the surface up to the height of the heights $60 \mathrm{~m}$ and $65 \mathrm{~m}$ respectively.
Sections L03 to L05, presented similar ZBR distributions in relation to sections $L 01$ and $L 02$, making a transition to the sections L06 and L08.

L04 regions of low resistivity were observed in sections L01 to L04, both along the right abutment as well as near the left abutment. To better understand these ZBR, a new campaign was made covering the left abutment, resulting in the sections L09 to L14. ZBRs are present in all sections, indicating a probable preferred water path. Comparing the results with the engineering project and the monitoring data of the dam, it is possible to observe remarkable coherence with the results of electric resistivity. The ZBRs seen in sections L01 and L02 correspond to the clay landfill region and the sand filter longitudinal to the axis. The clayey landfill, due to its physical properties, naturally has a much higher moisture content compared to the limestone landfill observed in the deepest part of these sections. In sections L06 and L08, the ZBR is consistent with the water levels observed in the INA's 11, 12 and 13, around $40 \mathrm{~m}$ elevation, which is probably already the groundwater surface.

In the new sections near the left abutment, the persistence of ZBRs occurred in an expressive way (Figure 2).

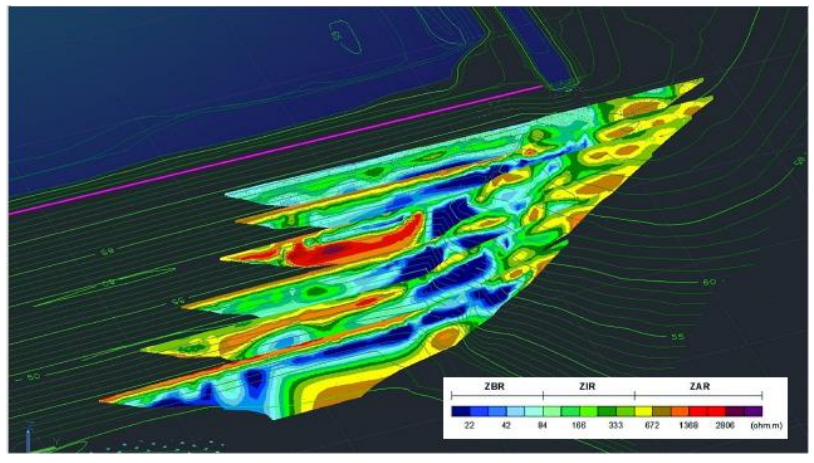

Figure 2 - Electric Resistivity profiles L09 to L14, from top to the bottom.

Through in-depth analyzes of the engineering projects and dialogues with the engineers responsible for the dam, information was obtained that some ladder concrete structures were maintained during construction (Figure 3).



Figure 3 - Old spillway discharge channels (white and red). Actual spillway in orange. 
They are old spillway discharge channels, being filled by a draining carpet, formed by stone crushed and sand, that began to serve as drains next to the left abutment. It is possible to notice that the ZBRs coincide with the location of the old spillway channels, demonstrating that the high porosity of the material in which they were filled (gravel and sand), allows water percolation, resulting in low resistive zones in the electrical sections Figure 4).

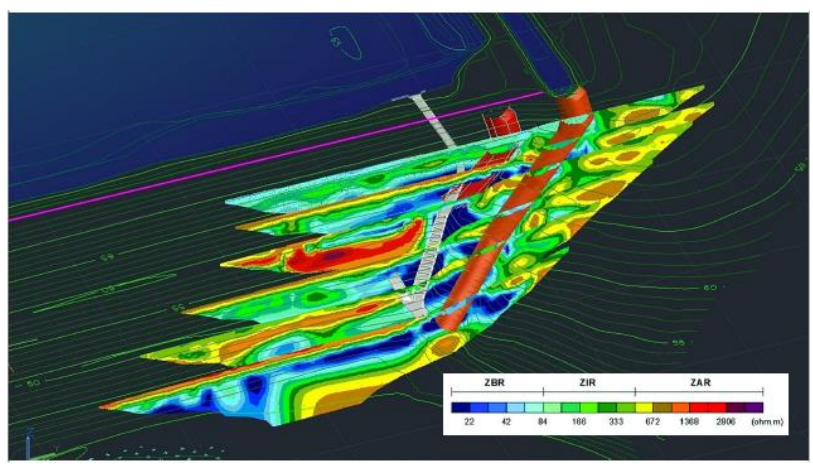

Figure 4 - The ZBRs coincide with the old and actual spillway channels.

\section{Conclusions}

It is observed that the data obtained with the application of Electric Resistivity are consistent with the existing information on the structure of the massif, being in harmony with the measurements of the instruments that monitor the dam. The geophysics, complementing the instrumentation, gives a broad view on the distribution of moisture and / or water in the massif, showing its behavior in stretches that are not covered by the instrumentation.

\section{Acknowledgments}

We thank Mosaic Fertilizantes for funding this work and allowing access to the data of Dam B1.

\section{References}

JOHANSSON, S. Seepage Monitoring in Embankment Dams. Royal Institute of Technology Stockholm, Doctoral Thesis, 50 p., 1997.

MAINALI, G. Monitoring of Tailings Dams with Geophysical Methods. Luleå University of Technology, Licentiate Thesis, 74 p., 2006.

PANTHULU, T.V.C.; KRISHNAIAH, C. \& SHIRKE, J.M. Detection of seepage paths in earth dams using selfpotential and electrical resistivity methods. Engineering Geology, 59: 281-295, 2001.

SJÖDAHL, P.T.; DAHLIN, S.; JOHANSSON, S. \& LOKE, M.H. Using resistivity measurements for dam safety evaluation at Enemossen tailings dam in southern Sweden. Environmental Geology 49: 267-273, 2005.

SJÖDAHL, P.T.; DAHLIN, S.; JOHANSSON, S. \& LOKE, M.H. Resistivity monitoring for leakage and internal erosion detection at Hällby embankment dam. Journal of Applied Geophysics, 65: 155-164, 2008. 